\title{
Detection of cytomegalovirus DNA in fecal samples in the diagnosis of enterocolitis after allogeneic stem cell transplantation
}

\author{
Alzbeta Zavrelova ${ }^{a}$, Jakub Radochaa ${ }^{a}$ Lenka Pliskova ${ }^{b}$, Pavla Paterovac, Eva Vejrazkova ${ }^{a}$, Jiri Cyrany ${ }^{d}$, Filip Gabalec, \\ Miroslav Podholae, Pavel Zak
}

Background. Cytomegalovirus enterocolitis is a rare but potentially life threatening complication after allogeneic stem cell transplantation. Its early diagnosis and treatment are essential for a successful outcome.

Objective. To determine the potential benefit of fecal CMV DNA detection in the diagnosis of CMV colitis among stem cell transplant recipients.

Study design. Biopsies from the lower gastrointestinal tract, taken during 69 episodes of diarrhea, were compared with fecal samples previously examined for CMV DNA in 45 patients after allogeneic stem cell transplantation.

Results. Six confirmed cases of CMV colitis were observed, with 16 out of 69 (23\%) fecal samples proving positive for CMV DNA. Only one positive sample correlated with histologically confirmed CMV colitis, and 15 samples were evaluated as false positive. These results provide a $16.7 \%$ sensitivity and $76.2 \%$ specificity in the diagnosis of CMV enterocolitis. Conclusion. The examination of fecal samples for the presence of CMV DNA has very low potential in the diagnosis of CMV enterocolitis after allogeneic stem cell transplantation; therefore, a biopsy of the gastrointestinal mucosa is still warranted for correct diagnosis.

Key words: CMV infection, CMV enterocolitis, allogeneic stem cell transplantation

Received: December 11, 2017; Accepted with revision: April 17, 2018; Available online: May 16, 2018 https://doi.org/10.5507/bp.2018.023

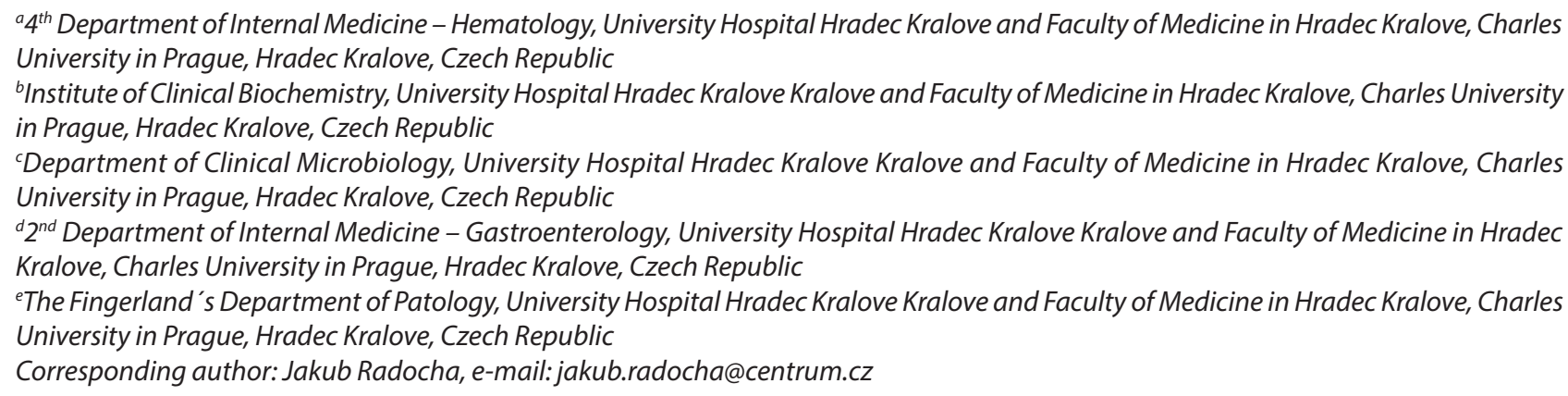

\section{INTRODUCTION}

The transplantation of allogeneic stem cells frequently leads to various gastrointestinal complications that could be the source of major morbidity and mortality among allogeneic transplant recipients. Graft versus host disease (GVHD), infections, and the toxicity of previous treatments are the major cause of gastrointestinal problems in these patients ${ }^{1,2}$. An early diagnosis, followed by adequate treatment, is the most important prerequisite of any successful therapy. During recent years, several invasive and non-invasive diagnostic methods have been developed, and though their clinical results are available within a very short time their validation in stem cell transplant recipients is still lacking.

Cytomegalovirus (CMV) is a common herpes virus that can become reactivated in an immunocompromised host, especially after stem cell transplantation ${ }^{3}$, causing a wide variety of end organ damage ${ }^{4}$, with pneumonia and enterocolitis being the most common stem cell transplant recipients 5 . The incidence of CMV induced enterocolitis is of $\sim 2 \%$ among transplant recipients, although its diagnosis remains challenging since there is neither a unique clinical picture nor a specific laboratory test ${ }^{6}$. The widely accepted diagnostic criteria is based on clinical symptoms, macroscopic findings through endoscopy, and histological analyses (culture, histopathology, immunohistochemical analysis, or in situ hybridization) ( ref. $^{7}$ ). Obtaining the biopsies might be complicated in transplant recipients and potentially lead to severe complications ${ }^{8,9}$. CMV detection by PCR in fecal samples could replace invasive techniques; therefore, the aim of the present study was determine the detection capacity of CMV DNA by PCR in fecal samples.

\section{STUDY DESIGN}

\section{Patients and specimens}

We performed a retrospective review of all patient's charts, including reports from lower gastrointestinal tract biopsies from patients presenting diarrhea after stem cell transplantation. The evaluation consisted of samples 
obtained from January 2008 to July 2015, only the peripheral blood and fecal samples from single episode of diarrhea were analyzed by PCR. Since no additional tests were done and this was purely retrospective chart analysis, an informed consent by the patients was not deemed necessary. The clinical data was obtained from patients' charts and independently reviewed by two physicians AZ and JR.

\section{Histopathology analysis}

CMV immunohistochemistry is part of the routine examination of patient's samples. Sections of $2 \mu \mathrm{m}$ in thickness were stained with hematoxylin/eosin for light microscopy examination. For immunohistochemical analysis, $3 \mu \mathrm{m}$ sections were immunostained using a Ventana autostainer ultraview detection kit (Ventana). Immunohistochemical studies were performed using monoclonal mouse anti - cytomegalovirus, clones CCH2+DDG9 (DAKO Denmark, dilution 1:100).

\section{PCR analysis}

CMV viremia was determined by qPCR from peripheral blood. DNA extraction was performed using a QIAamp DNA Mini Kit (Qiagen), quantitative DNA determination by CMV RG PCR (Qiagen) with 500 copies per $\mathrm{ml}$ of full peripheral blood $(\mathrm{cp} / \mathrm{mL})$ as the quantification cut off, and $100 \mathrm{cp} / \mathrm{mL}$ (i.e. $79.4 \mathrm{UI} / \mathrm{mL}$ ) as the detection cut off. For fecal analysis, viral DNA was extracted from stool samples after dilution and centrifugation using a QIAamp DNA Mini Kit (Qiagen). CMV DNA was detected using the CMV RG PCR kit (Qiagen) in a RotorGene 3000. The detection limit was of 100 copies per sample; however, due to complicated interpretation and extremely variable stool amounts from the patients, the results are reported only as positive or negative.

\section{Definition of CMV enterocolitis case}

The diagnosis of CMV colitis was based on positive imunohistochemistry in correlation with clinical and endoscopic features according to previously published recommendations ${ }^{7}$. Graft versus host disease was confirmed by histology; other infectious etiologies were confirmed by specific microbiological sampling as per institutional standards. The toxicity of previous treatments was considered only in cases where other etiologies were excluded by microbiological sampling and non-descriptive histology, and endoscopic features were present.

\section{Statistical analysis}

The diagnostic test evaluation was performed using the MedCalc v 9.5.2.0 software (MedCalc Software bvba, Belgium). An unpaired sample $t$-test was used to compare serum CMV quantities, $(P<0.05)$ was considered statistically significant.

\section{RESULTS}

Intestinal tissue, fecal and serum samples were collected from 45 included patients during 69 episodes of
Table 1. Patient demographics.

\begin{tabular}{|c|c|c|}
\hline Patient characteristics & $\mathrm{n}$ & $\%$ \\
\hline \multicolumn{3}{|l|}{ Gender } \\
\hline Males & 32 & 71.1 \\
\hline Females & 13 & 28.9 \\
\hline \multicolumn{3}{|l|}{ Age } \\
\hline Median & 54 & \\
\hline Minimum & 19 & \\
\hline Maximum & 69 & \\
\hline \multicolumn{3}{|l|}{ Diagnosis } \\
\hline AML & 15 & 33.3 \\
\hline ALL & 8 & 17.8 \\
\hline T-NHL & 6 & 13.3 \\
\hline CLL & 5 & 11.1 \\
\hline HL & 2 & 4.4 \\
\hline MPD & 8 & 17.8 \\
\hline MDS & 1 & 2.2 \\
\hline \multicolumn{3}{|l|}{ Type of transplant } \\
\hline Sibling & 7 & 15.6 \\
\hline MUD & 38 & 84.4 \\
\hline \multicolumn{3}{|c|}{ thymoglobulin during preparative regimen } \\
\hline Yes & 39 & 86.7 \\
\hline No & 6 & 13.3 \\
\hline \multicolumn{3}{|c|}{ CMV status (recipient/donor) } \\
\hline positive/negative & 22 & 48.9 \\
\hline positive/positive & 17 & 37.8 \\
\hline negative/negative & 3 & 6.7 \\
\hline negative/positive & 3 & 6.7 \\
\hline
\end{tabular}

$\mathrm{AML}=$ acute myeloid leukemia, $\mathrm{ALL}=$ acute lymphoblastic leukemia, $\mathrm{T}-\mathrm{NHL}=\mathrm{T}-$ non Hodgkin lymphoma, CLL $=$ chronic lymphocytic leukemia, $\mathrm{HL}=$ Hodgkin lymphoma, $\mathrm{MPD}=$ myeloproliferative disease, MDS $=$ myelodysplastic syndrome, $\mathrm{MUD}=$ matched unrelated donor .

Table 2. Causative etiology of diarrhoea and demographic data in CMV colitis cases.

\begin{tabular}{lrc}
\hline & $\mathbf{n}$ & $\%$ \\
\hline Identified causes of diarrhea & \multicolumn{2}{c}{} \\
CMV & 32 & 46.4 \\
GVHD & 9 & 13.0 \\
Infection & 18 & 26.1 \\
Toxic & 4 & 5.8 \\
Other & 69 & \\
Total & \\
CMV status in CMV colitis patients (recipient/donor) \\
positive/positive & 2 & 33.3 \\
negative/negative & 0 & 0.0 \\
positive/negative & 4 & 66.7 \\
negative/positive & 0 & 0.0 \\
thymoglobulin in CMV colitis patients & \multicolumn{2}{c}{} \\
Yes & 5 & 83.3 \\
No & 1 & 16.7 \\
\hline
\end{tabular}

GVHD $=$ graft versus host disease 
diarrhea. The complete data on demographics and disease status is shown in Table 1. CMV enterocolitis was diagnosed in 6 episodes in the same number of individual patients (i.e. no patient had two episodes of CMV colitis). Other diagnoses included 32 cases of GVHD, 9 infections (mainly clostridium enterocolitis and norovirus), 18 toxic damage after previous treatment, and 4 other cases (EBV gastrointestinal involvement in two patients with post-transplant lymphoproliferative disease, 1 large tubulovilous adenoma, 1 inflammatory bowel disease), details are shown in Table 2. Fig. 1 shows positive immunohistochemistry CMV staining and Fig. 2 shows negative results as an example. Sixteen out of sixty-nine (23\%) fecal samples were positive for CMV DNA, only 1 of $6(16.7 \%)$ CMV enterocolitis episodes correlated with positive CMV DNA in faeces. Fifteen samples were evaluated as false positive (positive fecal CMV DNA without evidence of CMV colitis). This resulted in $16.7 \%$ sensitivity and $76.2 \%$ specificity in the diagnosis of CMV enterocolitis by CMV PCR in fecal samples (Table 3).

Twenty-two of sixty-nine (32\%) blood samples were positive for DNA CMV, of these 4 samples were positive episodes of CMV enterocolitis. This resulted in $66.7 \%$ sensitivity and $71.4 \%$ specificity in the diagnosis of CMV enterocolitis (Table 3 ). The median number of copies per $\mathrm{mL}$ in peripheral blood was not statistically significantly different between cases of CMV and non-CMV colitis (530 copies/mL versus 498 copies/mL, respectively; $P=0.34)$.

\section{DISCUSSION}

According to current practice guidelines, the diagnosis of CMV enterocolitis requires a gut biopsy ${ }^{7,10,11}$. The diagnosis of CMV enterocolitis by CMV DNA detection in peripheral blood or antigenemia testing has yielded conflicting results; although some degree of accuracy has been observed in non-stem cell transplant patients. Durand et al. ${ }^{12}$ showed an $85 \%$ sensitivity and 95\% speci-

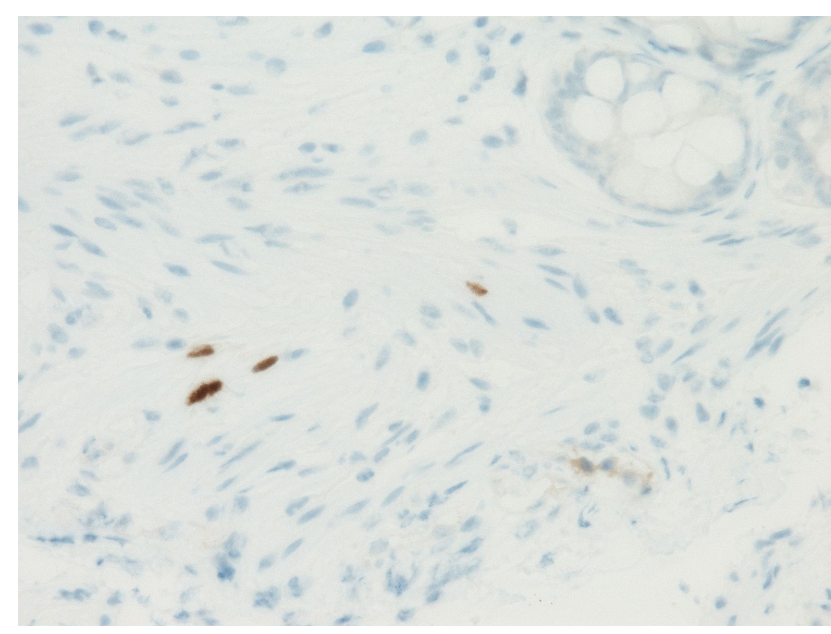

Fig. 1. Positive CMV immunohistochemistry staining. Dark dots are CMV positive endothelial cell.
Table 3. Predictive values of blood and faecal PCR CMV samples for diagnosis of CMV enterocolitis.

\begin{tabular}{lcc}
\hline Statistic & Value & 95\% CI \\
\hline Faecal PCR CMV predictive values & \\
Sensitivity & $\mathbf{1 6 . 6 7 \%}$ & $0.42 \%$ to $64.12 \%$ \\
Specificity & $76.19 \%$ & $63.79 \%$ to $86.02 \%$ \\
Positive Likelihood Ratio & 0.70 & 0.11 to 4.42 \\
Negative Likelihood Ratio & 1.9 & 0.75 to 1.61 \\
Disease prevalence & $8.70 \%$ & $3.26 \%$ to $17.97 \%$ \\
Positive Predictive Value & $\mathbf{6 . 2 5} \%$ & $0.16 \%$ to $30.23 \%$ \\
Negative Predictive Value & $90.57 \%$ & $79.34 \%$ to $96.87 \%$ \\
\hline Peripheral full blood PCR CMV predictive values \\
Sensitivity & $\mathbf{6 6 . 6 7 \%}$ & $22.28 \%$ to $95.67 \%$ \\
Specificity & $71.43 \%$ & $58.65 \%$ to $82.11 \%$ \\
Positive Likelihood Ratio & 2.33 & 1.17 to 4.64 \\
Negative Likelihood Ratio & 0.47 & 0.15 to 1.46 \\
Disease prevalence & $8.70 \%$ & $3.26 \%$ to $17.97 \%$ \\
Positive Predictive Value & $\mathbf{1 8 . 1 8 \%}$ & $5.19 \%$ to $40.28 \%$ \\
Negative Predictive Value & $95.74 \%$ & $85.46 \%$ to $99.48 \%$ \\
\hline
\end{tabular}

ficity when diagnosing CMV enterocolitis through plasma PCR testing among kidney and liver transplant patients; further, a strong diagnostic tool has also been found in CMV antigenemia testing ${ }^{13}$. However, the opposite has been found in stem cell transplant recipients, which show limited reliability for these assays. In a study by Mori et al. ${ }^{14}$ only $50 \%$ of patients with CMV enterocolitis yielded positive results from real-time PCR analysis of blood samples before developing CMV-GI disease. This low reliability might be caused by regular blood testing for CMV DNA and an early start of pre-emptive treatment, which is not the case in non-stem cell transplant recipients. This fact might potentially mimic the reactivation in specific predisposed end organs. In the present study, we have confirmed the low sensitivity and specificity of blood CMV DNA testing in stem cell transplant recipients.

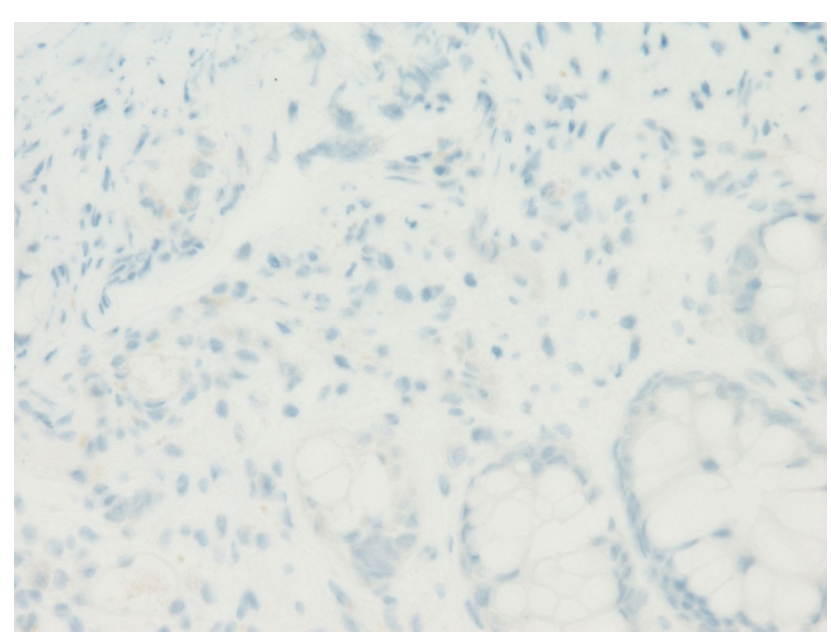

Fig. 2. Negative CMV immunohistochemistry staining. 
Since molecular methods are being validated for fecal samples in the diagnosis of other types of viral gastroenteritis ${ }^{15,16}$, we attempted to improve the diagnostic strategy for CMV colitis by detecting DNA CMV in these samples. However, only scarce data has been published suggesting that the detection of DNA CMV in fecal samples might add some value for the differential diagnosis of diarrhea in immunocompromised patients and patients with inflammatory bowel disease (IBD). According to a study by Ganzenmueller et al. ${ }^{17}$, conducted on immunocompromised patients (68\% stem cell or solid organ transplantation), the PCR analysis from fecal samples were positive in 8 out of 12 patients with CMV enterocolitis. This data was confirmed by Michel et al. ${ }^{18}$ in a study on immunocompromised patients where all 4 patients with CMV enterocolitis were tested positive in the PCR analysis of fecal samples, with only one false positive result. Similar data was published by Herfarth et al. ${ }^{19}$ on IBD patients, where the sensitivity and specificity of the PCR analysis in fecal samples diagnosing CMV enterocolitis was 83 and $93 \%$, respectively. However, we could not confirm these results in our study, which was aimed at a unique group of allogeneic stem cell transplant recipients and is one of the largest reported. Further, the correlation of fecal samples with the diagnosis of CMV enterocolitis was very low in our cohort, observing a high rate of false positive hits and even higher false negative results. Moreover, we would have missed $5 \mathrm{CMV}$ enterocolitis cases (83\%) had we solely relied on non-invasive techniques; to complicated matters further, we could have been administering the wrong treatment to 15 false positive patients.

Interestingly, GVHD of the gut preceded the development of CMV colitis in 5 of 6 patients, the only patient without precedent of GVHD suffered from IBD, suggesting a strong link with an impaired gut mucosa and further deterioration of the immune status due to GVHD and its treatment. Further, CMV disease might develop as a second hit disease, according to Boeckh et al who showed GVHD as a predictive factor for CMV disease development ${ }^{20}$. As described previously, seropositive patients are at highest risk of CMV disease development ${ }^{21}$ and in our study only CMV seropositive patients developed CMV enterocolitis, despite that four of these six patients had seronegative donors.

Our data suggest that a gut biopsy cannot be omitted when regarding CMV colitis because its diagnosis cannot be based only on non-invasive tests. Easily obtainable clinical data, such as CMV serostatus or history of GVHD, could facilitate the identification of patients prone to the development of CMV enterocolitis and thus determine if an invasive sampling is needed. Therefore, endoscopic examination will probably remain the gold standard for the diagnosis of patients after stem cell transplantation without an identifiable cause of diarrhea.

Acknowledgement: This work was supported by PROGRES Q40/8 and MH CZ - DRO (UHHK, 00179906). The authors wish to thank Dr. Daniel Díaz, Ph.D. for his kind assistance in English language revision and proofreading.
Author contributions: AZ, JR: analyzed the clinical data and wrote the manuscript, authors contributed equally to the manuscript preparation; LP: performed PCR analysis and wrote the manuscript; PP: reviewed microbiological data and wrote the manuscript; EV: reviewed the manuscript; JC: performed endoscopies and wrote the manuscript; FG: reviewed and wrote the manuscript; MP: performed histological examinations and wrote the manuscript; PZ: reviewed and approved the manuscript. Conflict of interest statement: None declared.

\section{REFERENCES}

1. Schulenburg A, Turetschek K, Wrba F, Vogelsang H, Greinix HT, Keil F, Mitterbauer M, Kalhs P. Early and late gastrointestinal complications after myeloablative and nonmyeloablative allogeneic stem cell transplantation. Ann Hematol 2004;83(2):101-6.

2. Cox GJ, Matsui SM, Lo RS, Hinds M, Bowden RA, Hackman RC, Meyer WG, Mori M, Tarr PI, Oshiro LS. Etiology and outcome of diarrhea after marrow transplantation: a prospective study. Gastroenterology 1994;107(5):1398-407.

3. Cannon MJ, Schmid DS, Hyde TB. Review of cytomegalovirus seroprevalence and demographic characteristics associated with infection. Rev Med Virol 2010;20(4):202-13.

4. Ariza-Heredia EJ, Nesher L, Chemaly RF. Cytomegalovirus diseases after hematopoietic stem cell transplantation: a mini-review. Cancer Lett 2014;342(1):1-8.

5. Wingard JR, Piantadosi S, Burns WH, Zahurak ML, Santos GW, Saral R. Cytomegalovirus infections in bone marrow transplant recipients given intensive cytoreductive therapy. Rev Infect Dis 1990;12 Suppl 7:S793-804

6. van Burik JA, Lawatsch EJ, DeFor TE, Weisdorf DJ. Cytomegalovirus enteritis among hematopoietic stem cell transplant recipients. Biol Blood Marrow Transplant 2001;7(12):674-9.

7. Ljungman $P$, Griffiths $P$, Paya $C$. Definitions of cytomegalovirus infection and disease in transplant recipients. Clin Infect Dis 2002;34(8):1094-7.

8. Fisher DA, Maple JT, Ben-Menachem T, Cash BD, Decker GA, Early DS, Evans JA, Fanelli RD, Fukami N, Hwang JH, Jain R, Jue TL, Khan KM, Malpas PM, Sharaf RN, Shergill AK, Dominitz JA. Complications of colonoscopy. Gastrointest Endosc 2011;74(4):745-52.

9. Arora G, Mannalithara A, Singh G, Gerson LB, Triadafilopoulos G. Risk of perforation from a colonoscopy in adults: a large populationbased study. Gastrointest Endosc 2009;69(3):654-64.

10. Reddy N, Wilcox CM. Diagnosis \& management of cytomegalovirus infections in the GI tract. Expert Rev Gastroenterol Hepatol 2007; 1(2):287-94

11. You DM, Johnson MD. Cytomegalovirus infection and the gastrointestinal tract. Curr Gastroenterol Rep 2012;14(4):334-42.

12. Durand CM, Marr KA, Arnold CA, Tang L, Durand DJ, Avery RK, Valsamakis A, Neofytos D. Detection of cytomegalovirus DNA in plasma as an adjunct diagnostic for gastrointestinal tract disease in kidney and liver transplant recipients. Clin Infect Dis 2013;57(11):1550-9.

13. Nagata N, Kobayakawa M, Shimbo T, Hoshimoto K, Yada T, Gotoda T, Akiyama J, Oka S, Uemura N. Diagnostic value of antigenemia assay for cytomegalovirus gastrointestinal disease in immunocompromised patients. World J Gastroenterol 2011;17(9):1185-91.

14. Mori T, Mori S, Kanda Y, Yakushiji K, Mineishi S, Takaue Y, Gondo H, Harada M, Sakamaki H, Yajima T, Iwao Y, Hibi T, Okamoto S. Clinical significance of cytomegalovirus (CMV) antigenemia in the prediction and diagnosis of CMV gastrointestinal disease after allogeneic hematopoietic stem cell transplantation. Bone Marrow Transplant 2004;33(4):431-4.

15. Rolfe KJ, Parmar S, Mururi D, Wreghitt TG, Jalal H, Zhang H, Curran MD. An internally controlled, one-step, real-time RT-PCR assay for norovirus detection and genogrouping. J Clin Virol 2007;39(4):318-21.

16. Khamrin $P$, Okame $M$, Thongprachum $A$, Nantachit $N$, Nishimura $S$, Okitsu S, Maneekarn N, Ushijima H. A single-tube multiplex PCR 
for rapid detection in feces of 10 viruses causing diarrhea. J Virol Methods 2011;173(2):390-3.

17. Ganzenmueller T, Kluba J, Becker JU, Bachmann O, Heim A. Detection of cytomegalovirus (CMV) by real-time PCR in fecal samples for the non-invasive diagnosis of CMV intestinal disease. J Clin Virol 2014;61(4):517-22.

18. Michel D, Marre E, Hampl W, Roczkos J, Müller S, Hertenstein B, Kern P, Heymer B, Salzberger B, Arasteh K. Intestinal cytomegalovirus disease in immunocompromised patients may be ruled out by search for cytomegalovirus DNA in stool samples. J Clin Microbiol 1995;33(11):3064-7.

19. Herfarth $H H$, Long $M D$, Rubinas $T C$, Sandridge $M$, Miller $M B$. Evaluation of a non-invasive method to detect cytomegalovirus
(CMV)-DNA in stool samples of patients with inflammatory bowel disease (IBD): a pilot study. Dig Dis Sci 2010;55(4):1053-8.

20. Boeckh $M$, Leisenring $W$, Riddell SR, Bowden RA, Huang M-L, Myerson D, Stevens-Ayers T, Flowers ME, Cunningham T, Corey L. Late cytomegalovirus disease and mortality in recipients of allogeneic hematopoietic stem cell transplants: importance of viral load and T-cell immunity. Blood 2003;101(2):407-14.

21. Nichols WG, Corey L, Gooley T, Davis C, Boeckh M. High risk of death due to bacterial and fungal infection among cytomegalovirus (CMV)-seronegative recipients of stem cell transplants from seropositive donors: evidence for indirect effects of primary CMV infection. J Infect Dis 2002;185(3):273-82. 